\title{
Structure and heat content of the West Spitsbergen Current
}

\author{
Peter M. Haugan
}

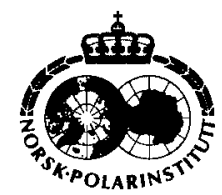

The seasonal evolution of the hydrographic structure of the West Spitsbergen Current (WSC) above bottom depths from $300 \mathrm{~m}$ to $800 \mathrm{~m}$ is discussed based on a modern data set with high spatial resolution. The WSC appears to have a core with high temperature and salinity, linked to the topography in this depth interval, with a width on the order of $10 \mathrm{~km}$. Strong cooling occurs in the autumn, reducing the heat content of the upper $200 \mathrm{~m}$, but advected temperature and salinity maxima survive close to the surface in spring when air--sea exchange and vertical mixing is hampered by sea ice and meltwater.

P. M. Haugan, Geophysical Institute, University of Bergen, Allegaten 70, N-5007 Bergen, Norway.

\section{Introduction}

The West Spitsbergen Current (WSC) is the northernmost extension of the Norwegian Atlantic Current which is known to transport substantial amounts of heat from the North Atlantic into the Arctic Mediterranean. Fram Strait contains the northernmost permanently ice-free ocean area on earth. Global coupled model greenhouse gas scenario runs (Washington \& Meehl 1996) indicate warming in the continuation of the WSC in the Atlantic layer of the Arctic Ocean and reduction of ice cover with implications for global albedo. Arctic ice extent has reduced and the temperature of the Atlantic layer has increased in recent years (Grotefendt et al. 1998), apparently linked to warming of the deep water in the Greenland Sea and changes in the atmospheric circulation towards north-west Europe expressed as an increased North Atlantic Oscillation (NAO) index (Hurrell \& van Loon 1997). If such tentative large-scale patterns and links are significant in the natural or perturbed climate system it seems that the WSC must play an important role as the mediator between the North Atlantic oceanic system and the Arctic.

This paper is concerned with the inner part of the WSC which feeds the coastal branch shown in Fig. 1, subducting below the surface and continuing into the Arctic Ocean as the Atlantic layer. While the outer parts of the WSC over deep water may be dominated by large baroclinic eddies and recirculate in complex ways difficult to monitor, it is our hypothesis that the inner branch over the continental slope may be suitable to time series observations and perhaps respond in meaningful ways to large-scale forcing anomalies.

The hydrography over the continental slope of west Spitsbergen in the depth interval $300 \mathrm{~m}$ to $800 \mathrm{~m}$ was studied. The shallow depth limit was chosen because it eliminates shelf observations clearly east of the WSC core while still allowing detection of the shoreward extent of the current and its mixing with shelf water. The deep depth limit was selected to allow detection of the boundary between Atlantic water above intermediate water. The present state is examined on the basis of a recent high quality seasonal data set with high spatial resolution. Processes involved in determining the structure of the WSC, relations to the few published seasonal data available, and requirements for future monitoring are briefly discussed.

\section{Observations}

Most recent measurement campaigns (e.g. Gascard et al. 1995; W. Walcowski, pers. comm. 1998) have been performed in summer; the November data of Aagaard et al. (1987) and the January- 


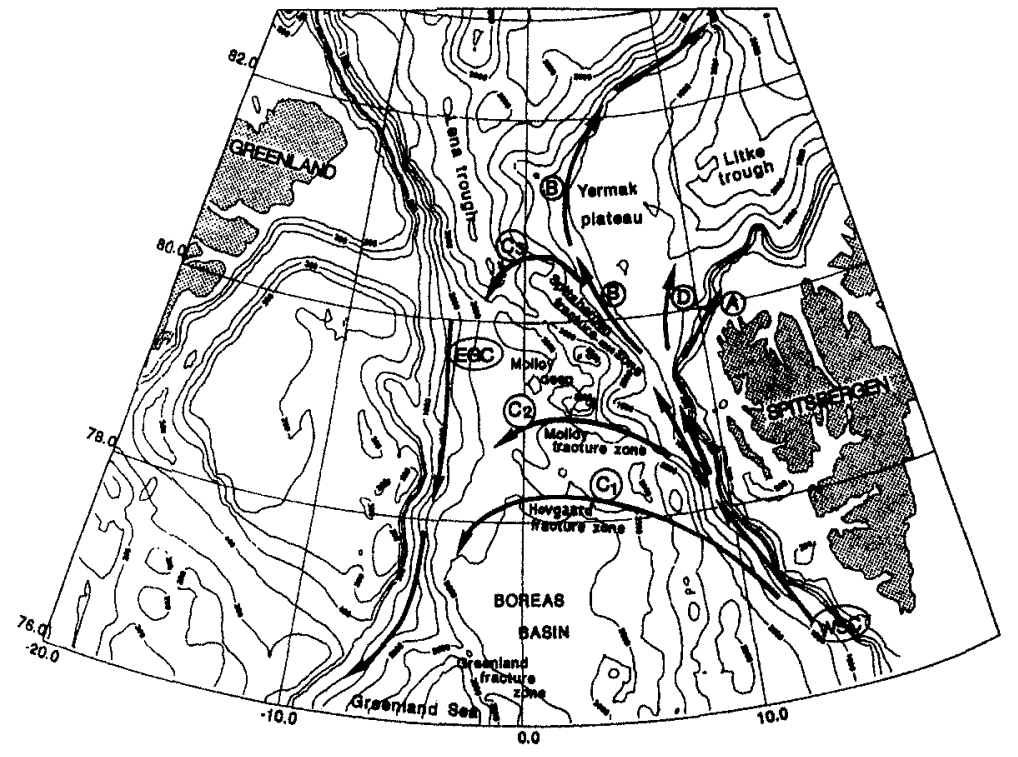

Fig. 1. Branching of the WSC according to Gascard et al. (1995). The location of our repeat section (from $77^{\circ} 38^{\prime} \mathrm{N}$. $10^{\circ} 33^{\prime} \mathrm{E}$ to $77^{\circ} 39^{\circ} \mathrm{N}, 10^{\circ} 45^{\prime} \mathrm{E}$ ) is indicated.
February data of Boyd \& D'Asaro (1994) are notable exceptions. Between the summers of 1997 and 1998, we monitored the WSC with detailed hydrographic observations using a Seabird CTD system. A cruise planned in February 1998 had to be cancelled since the ship had technical difficulties in the very cold weather (around $-30^{\circ} \mathrm{C}$ ) at the time. During a cruise which was completed in April/May, heavy drift ice made it impossible to navigate into fixed positions on the shelf slope. The ice conditions along the west coast of Spitsbergen were heavy in winter and spring 1998 with much multi-year ice until the last week of May.

Stations were established over $300 \mathrm{~m}, 400 \mathrm{~m}$, $500 \mathrm{~m}, 600 \mathrm{~m}, 700 \mathrm{~m}$ and $800 \mathrm{~m}$ depths on the section marked in Fig. 1 on 20 September 1997, 19 November 1997, 3-4 June 1998 and 4 September 1998. The section is perpendicular to the topography and only $9 \mathrm{~km}$ long stretching from approximately $77^{\circ} 38^{\prime} \mathrm{N}, 10^{\circ} 33^{\prime} \mathrm{E}$ to $77^{\circ} 39^{\prime} \mathrm{N}$, $10^{\circ} 45^{\prime} \mathrm{E}$. The station spacing is $1.5 \mathrm{~km}$ except in the shallowest part where the slope is less steep. The numerical value of the slope is at a maximum of about 0.07 in the depth interval $400 \mathrm{~m}$ to $800 \mathrm{~m}$ and decreases again to about 0.03 between $1000 \mathrm{~m}$ and $2000 \mathrm{~m}$ depth. The late November and early June cruises can be considered as taking place at the beginning and end of winter, respectively, while the September data are representative of the local summer peak.
Figure 2 shows the seasonal evolution of temperature, while salinity is shown in Fig. 3. Detailed profiles and a temperature-salinity diagram from the $600 \mathrm{~m}$ depth station are shown in Fig. 4. There is an average reduction in temperature of about $1{ }^{\circ} \mathrm{C}$ in the upper $200 \mathrm{~m}$ during the two months from September to November (Figs. $2 \mathrm{a}, \mathrm{b})$. The cooling has been associated with a reduction in salinity on the order of 0.1 psu (Figs. $3 a, b)$, so that the core salinity above 35 is now only present in a thin layer below $200 \mathrm{~m}$. The freshening may be due to in-mixing of sea ice meltwater from the western Barents Sea or influence from coastal water. The rate of reduction in local upper ocean heat storage corresponds to a net heat release of about $150 \mathrm{Wm}^{-2}$ during the two month period. This time rate of change term is a significant contribution to the surface heat budget in the autumn. It comes in addition to ocean heat flux divergence, which in principle can be determined from observations of northward cooling and current velocities (Aagaard et al. 1987; Boyd \& D'Asaro 1994).

In early June, water warmer than $4^{\circ} \mathrm{C}$ extends upwards to only $20 \mathrm{~m}$ depth, capped by a thin surface layer affected by sea ice meltwater (Fig. 2c). The high temperature water obviously originates from the northward flow of the WSC from warmer, ice-free regions further south. It can be seen from the shallow and strong salinity maximum (Fig. 3c) that there has been little mixing 

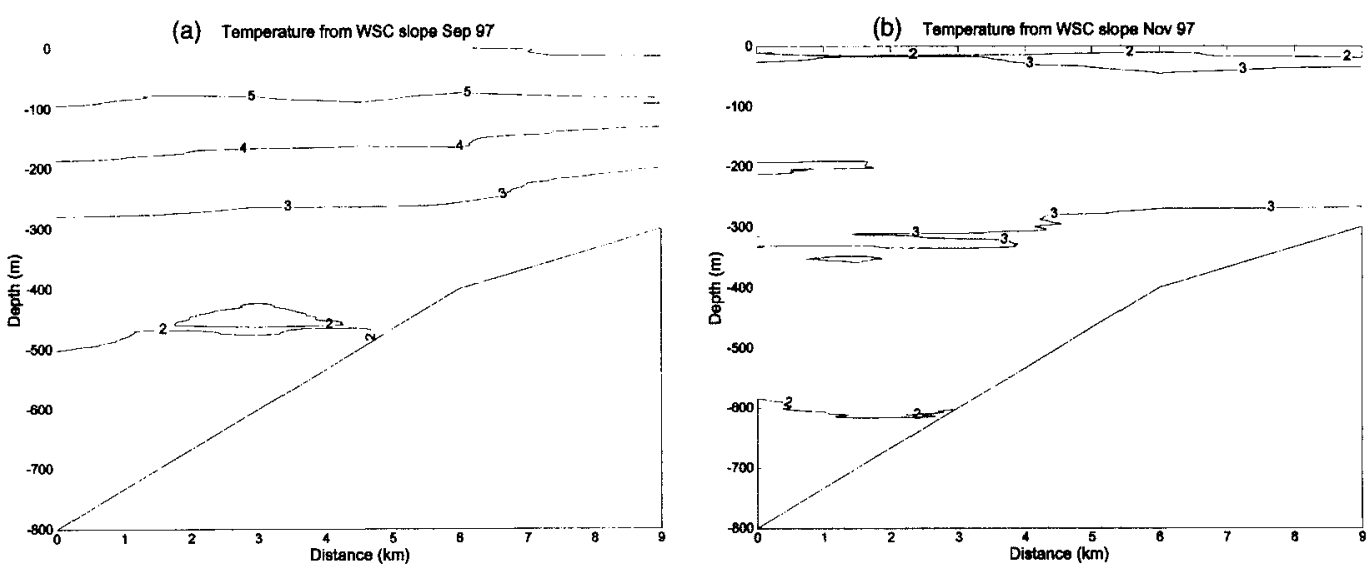

(c) Temperature from WSC slope Jun 88
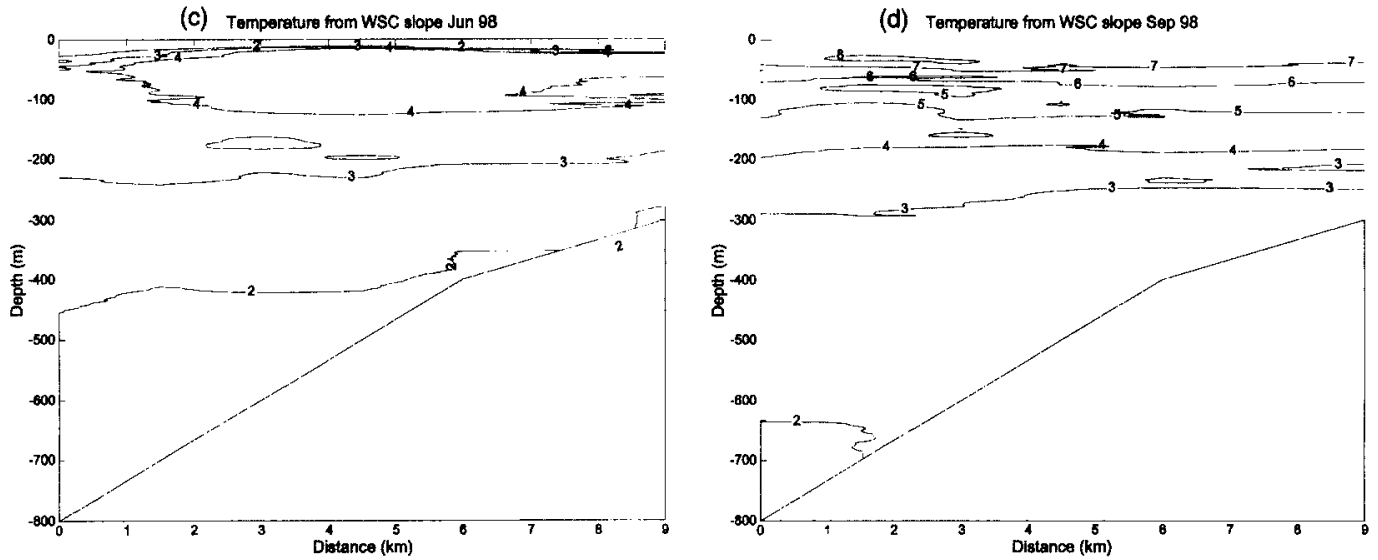

Fig. 2. Temperature sections: (a) September 1997; (b) November 1997; (c) June 1998; and (d) September 1998.

with the low salinity surface water, which has been isolated from the water below by a strong density stratification at the base of the mixed layer (not shown). In contrast, the shallow mixed layer observed in November, rests on top of a much more gradual and monotonous stratification in temperature and salinity, probably the result of previous vertical mixing events induced by transient wind forcing of the shallow mixed layer.

The highest temperatures and salinities in June occur over the slope region, but not further west above deeper water (Figs. 2c, 3c). This structure would be consistent with a swift jet situated over the strong topographic slope and weaker northward flow on the shelf and offshore. But it could also be that further west, the extreme properties have been eroded more strongly by isopycnal mixing or wind mixing from the surface.

In September 1998 the upper $50 \mathrm{~m}$ was almost
$2 \mathrm{C}$ warmer than in September 1997 (Figs. 2a, d, 4a). The survey in 1997 was 16 days later in the year than that in 1998 , but the cooling rate of $0.5^{\circ} \mathrm{C}$ per month estimated during autumn 1997 cannot explain more than a small fraction of this difference, which is ascribed to interannual variability.

Approximately neutrally buoyant, cold, low salinity anomalies occur on scales of $1-2 \mathrm{~km}$ in the horizontal and $10 \mathrm{~m}$ in the vertical, notably on the $600 \mathrm{~m}$ depth station at around $180 \mathrm{~m}$ depth in June, (Figs. 2c, 3c), and at around $90 \mathrm{~m}$ depth in September 1998 (Figs. 2d, 3d, 4a, 4b). It is proposed that the origin of these anomalies must be on the shelf east of the main core of the WSC, and that they propagate along isopycnals offshore into the WSC. The detailed mechanisms of transport and their role in cooling and dilution of the WSC remain speculative. As illustrated in Fig. 
(a) Salinity from WSC slope Sep 97

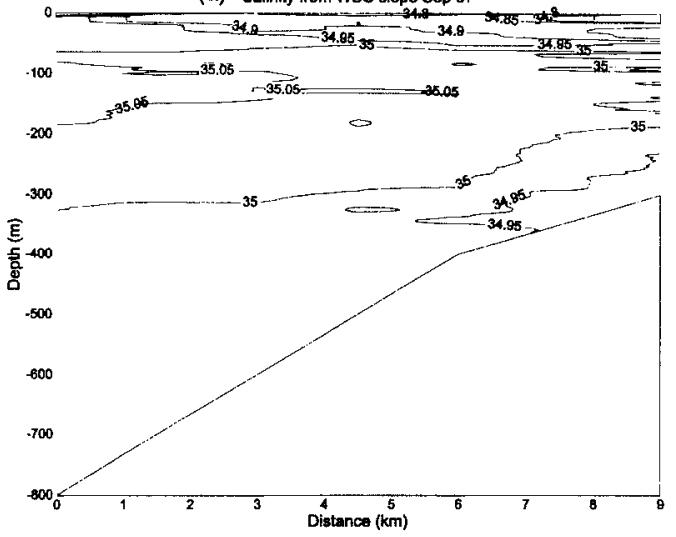

(c) Salinity from WSC slope Jun 98

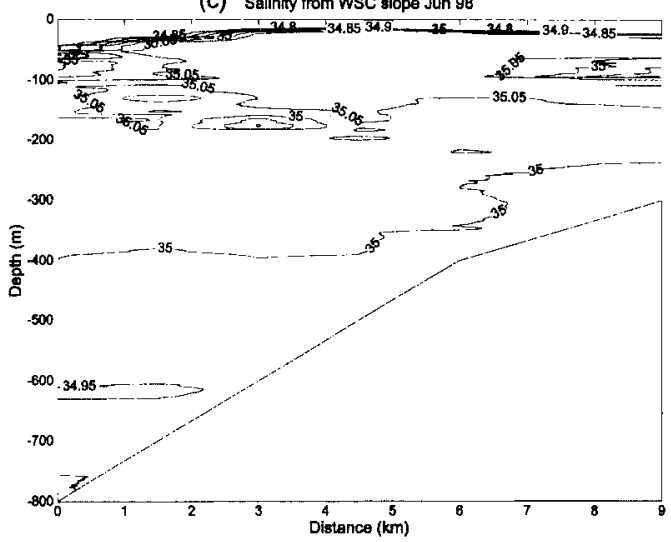

(b) Satinity from WSC slope Nov 97

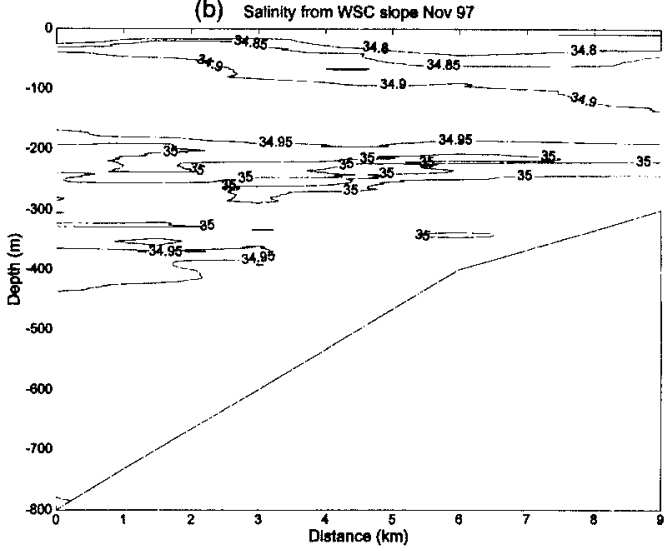

(d) Salinity from WSC slope Sep 98

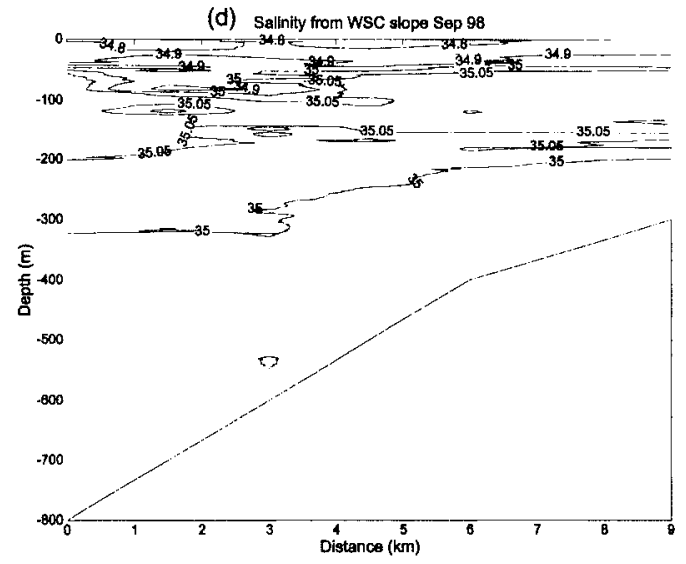

Fig. 3. Salinity sections: (a) September 1997; (b) November 1997: (c) June 1998; and (d) September 1998.

$4 c$, the water column is always stable with possibilities for marginal instability associated with these intrusions of cold, low salinity water.

\section{Discussion}

The structure of the inner parts of the WSC seems similar to that reported by Orvik et al. (1995) for the Norwegian Atlantic Current in the LofotenVesterålen area, i.e. a topographically steered, significantly barotropic current. The direct current measurements by Orvik et al. show a core over a similar depth interval along the slope as discussed here based only on hydrography. Although the distance to the upstream sections in the Norwegian Sea is considerable, there is a continuity between the two current systems, and similar driving mechanisms may be at work. The continental slope west of Spitsbergen is quite steep in this depth interval. Topographic steering is theoretically expected to be particularly important for high latitude currents based on conservation of potential vorticity. However, significant upslope motion has been reported by Richez (1998) north of our study area close to the Yermak plateau. The mechanisms behind such motion are partly unknown, and not necessarily applicable to the steep slope area where our measurements have been taken. The observed temperature and salinity maxima attached to the topographic slope could be reconciled with upslope motion if water mass modification on the shallow shelf is accounted for.

The data of Aaagaard et al. (1987), collected on 20-27 November 1977 at $79^{\circ}$ and $80^{\circ} \mathrm{N}$, showed temperature maxima of 3.5 to $4^{\circ} \mathrm{C}$ between $100 \mathrm{~m}$ and $200 \mathrm{~m}$ depth and maximum salinities close to 
Fig. 4. Temperature and salinity observations from the station at $600 \mathrm{~m}$ depth, September 1997 (thickest line), November 1997 (intermediate line thickness), June 1998 (dashed line), September 1998 (thinnest line): (a) temperature profiles; (b) salinity profiles; (c) temperature-salinity diagram, with potential density isolines included.
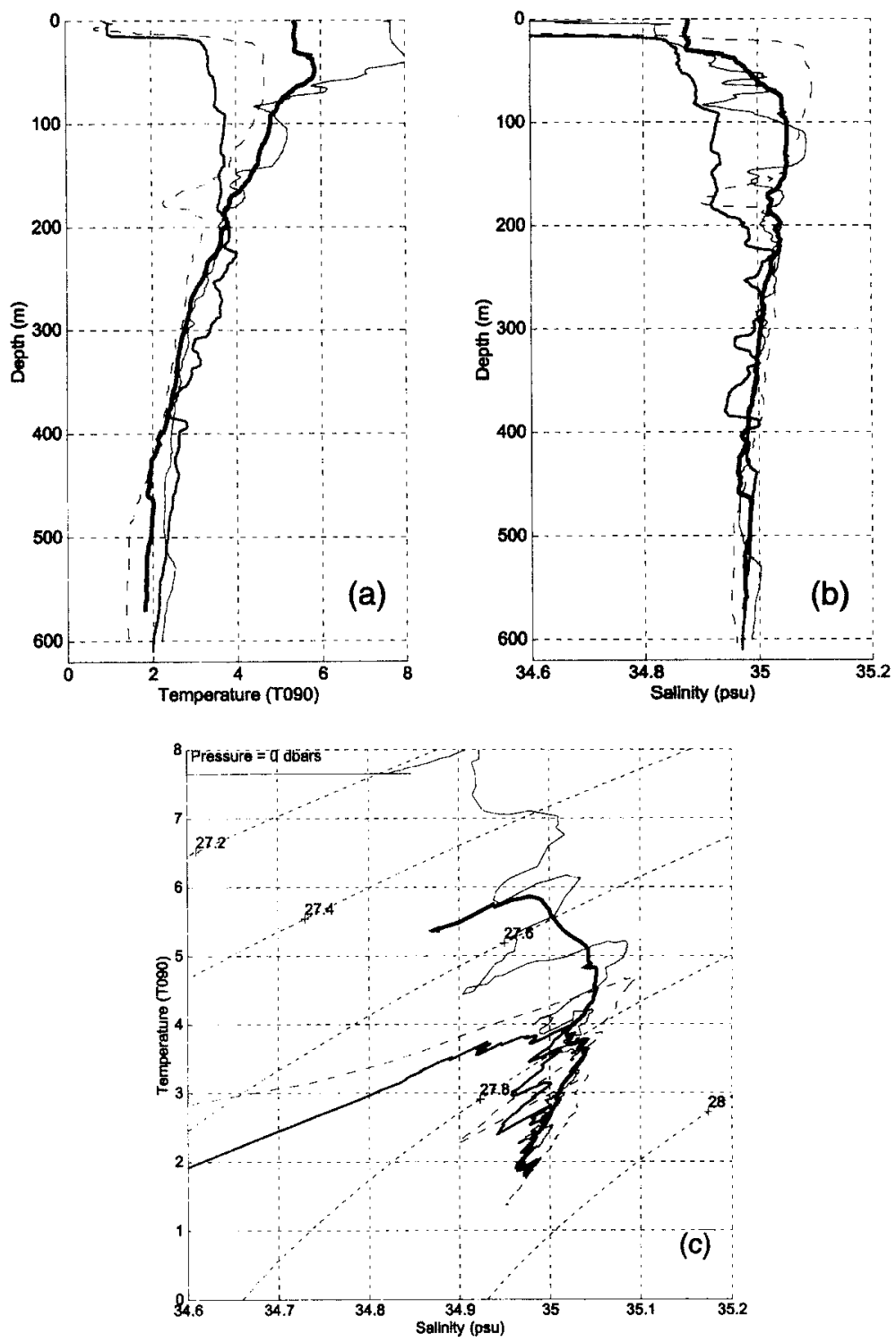

34.975 between $200 \mathrm{~m}$ and $300 \mathrm{~m}$ depth. These are close to the values of our November data obtained in another year and $150-300 \mathrm{~km}$ upstream. The data of Boyd \& D'Asaro (1994), collected in January and February 1989, show core temperatures above $4^{\circ} \mathrm{C}$ close to our repeat section. While, again, unknown interannual variability cannot be accounted for in comparisons, it does appear possible that such temperatures could have prevailed also in January-February 1998, i.e. that advectively generated local warming occurs below sea ice in winter.
Expecting heat loss over open water to be strongest in winter, the upstream conditions should provide warmer source waters for the WSC in fall than in spring. Nonetheless, assuming constant current speed, the data suggest that the early June situation with warm, saline water in the WSC subducted below surface meltwater seems more favourable for heat transport further north, and eventually into the Arctic Ocean, than the late November situation with a deeper mixed water column giving up large amounts of heat to the atmosphere locally. The situation may be more 
complex however, since seasonal variation in current speed may be significant. Morison (1991) reported seasonal variations in barotropic currents on the order of $10 \mathrm{~cm} / \mathrm{s}$ based on data from bottom pressure recorders during 1982 to 1985 north-west of Spitsbergen, with strongest current speeds in late fall, possibly related to maxima in wind forcing during that season.

Ice conditions in spring 1998 were severe in the area, but in summer and early autumn, near surface water was warm west and north of Svalbard (data not shown here). A possible explanation may be that the temperature in the WSC below the sea ice is kept high when large amounts of meltwater prevent vertical mixing, and that rather than giving up heat to the atmosphere or to ice melting, these warm waters penetrate with small modifications further north and become available for solar heating when the sea ice has finally disappeared.

\section{Conclusions}

The observational coverage of the seasonal cycle is limited, but has revealed strong cooling in the autumn and the persistence of strong temperature and salinity maxima at the end of winter. It is proposed that heavy ice conditions west of Spitsbergen during spring, generating a stable surface meltwater layer and consequent reduction in heat loss from the WSC, could lead to increased heat transport into the Arctic Ocean during summer. Such seasonal sea ice modulation of the advective heat transfer to the interior Arctic could also have interannual signatures in that heavy ice west of Spitsbergen in spring would precondition warm summers north of Svalbard. Much deeper studies and further monitoring of this coupled atmosphere-ice-ocean system is needed not only for climate change detection, but even for achiev- ing the more modest aim of understanding the seasonal cycle and its interannual variations.

Acknowledgements. - The captains and crew of Lance, Polarsyssel and Håkon Mosby as well as UNIS staff and students made the cruises pleasant. Vigdis Tverberg of UNIS has been a key person in establishing the UNIS CTD system and procedures for data analysis. The cruise in September 1998 was carried out in collaboration with Harald Svendsen of the Geophysical Institute, University of Bergen.

\section{References}

Aagaard, K., Foldvik, A. \& Hillman, S. R. 1987: The West Spitsbergen Current: disposition and water mass transformation. J. Geophys. Res. 92(C14), 3778-3784.

Boyd, T. J. \& D'Asaro, E. A. 1994: Cooling of the West Spitsbergen Current: wintertime observations west of Svalbard. J. Geophys. Res. 99(C11), 22597-22618.

Gascard, J. C., Richez, C. \& Rouault, C. 1995: New insights on large-scale oceanography in Fram Strait: the West Spitsbergen Current. In W. O. Smith \& J. M. Grebmeier (eds.); Arctic oceanography: marginal ice zones and continental shelves. Pp. 131-182. Washington D.C.: American Geophysical Union.

Grotefendt, K., Logemann, K., Quadfasel, D. \& Ronski, S. 1998: Is the Arctic Ocean warming? J. Geophys. Res. 103(C12), 27679-27687.

Hurrell, J. W. \& van Loon, H. 1997: Decadal variations in climate associated with the North Atlantic Oscillation. Clim. Change 36, 301-326.

Morison, J. 1991: Seasonal variations in the West Spitsbergen Current estimated from bottom pressure measurements. $J$. Geophys. Res. 96(C10), 18381-18395.

Orvik, K. A., Lundberg, L. \& Mork, M. 1995: Topographical influence on the flow field off Lofoten-Vesterålen. In H. Skjoldal et al. (eds.): Ecology of fjords and coastal waters. Pp. 165-175. Amsterdam: Elsevier Science.

Richez, C. 1998: The West Spitsbergen Current as seen by SOFAR floats during the ARCTEMIZ 88 Experiment: statistics, differential kinematic properties, and potential vorticity balance. J. Geophys. Res. 103(C8), 15539-15565.

Washington, W. M. \& Meehl, G. A. 1996: High-latitude climate change in a global coupled ocean-atmosphere-sea ice model with increased atmospheric $\mathrm{CO}_{2}$. J. Geophys. Res. 101(D8), 12795-12801. 